International Journal of Instruction e-ISSN: 1308-1470 • www.e-iji.net

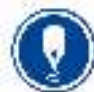

January $2020 \bullet$ Vol.14, No.1

p-ISSN: 1694-609X

pp. $813-826$

Article submission code:

20200223134058
Received: 23/02/2020

Revision: 02/08/2020
Accepted: 24/08/2020

OnlineFirst:28/11/2020

\title{
Components of Chinese Language Teacher's Functional Competencies: A Confirmatory Factor Analysis
}

\section{Yaowatida Siewseng}

King Mongkut's Institute of Technology Ladkrabang, Thailand, yaowatida13@gmail.com

Ampapan Tuntinakhongul

King Mongkut's Institute of Technology Ladkrabang, Thailand, ampapankmitl@gmail.com

\section{Pariyaporn Tungkunanan}

King Mongkut's Institute of Technology Ladkrabang, Thailand, pariyaporn.tu@kmitl.ac.th

This quantitative study was aimed at factor analysis of Chinese language teacher's functional competencies in Thai schools of Basic Education. The samples were collected with stratified random sampling technique, totaling 500 Chinese language teachers in schools of the Basic Education Commission, Ministry of Education in Thailand. The research instrument was the questionnaire with its reliability value of 0.96. The statistical analysis consisted of Confirmatory Factor Analysis (CFA), means (M), and standard deviation (S.D.). The data for analysis were the seven components of Chinese language teacher's functional competencies including: 1) Chinese Curriculum and Curriculum Development; 2) Creation of a Conducive Classroom Environment; 3) Psychology of Learning; 4) Development of Teacher Professionalism; 5) Communication Skills and Knowledge; 6) Understanding of Multiculturalism; and 7) ICT for Instructional Media Production. The findings presented that the components of Chinese language teacher's functional competencies correspond significantly with empirical data by a CFA $(\chi 2$-test $=0.81$, $\chi 2 / \mathrm{df}=0.12, \mathrm{RMR}=0.00, \mathrm{GFI}=1.00, \mathrm{AGFI}=0.99, \mathrm{RMSEA}=0.00)$.

Keywords: teacher's functional competencies, Chinese language teacher, Thailand components of Chinese language teacher, confirmatory factor analysis, language teacher

\section{INTRODUCTION}

The term 'competency' has been defined by various academics and scholars with similar points of view. McClelland (1973) first invented the term and stated that a competency as a characteristic hidden in an individual, which could drive the individual to show performances that met the predetermined criteria. Boyatzis (1982) further defined it as a

Citation: Siewseng, Y., Tuntinakhongul, A., \& Tungkunanan, P. (2021). Components of Chinese Language Teacher's Functional Competencies: A Confirmatory Factor Analysis. International Journal of Instruction, 14(1), 813-826. https://doi.org/10.29333/iji.2021.14149a 
principal characteristic of an individual leading to effective or superior performance which could be one of these features: motives, traits, skills, aspects of one's self images or bodies of knowledge. Spencer \& Spencer (1993) posited that competencies in an individual would govern the individual's behaviors and attitudes implemented to different situations, and those competencies could be divided into knowledge, skill, selfconcept, trait and motive. Lloyd and Cook (1993) defined competency as capability of running activities as expected. Davies \& Ellison (1997) pointed out that competency as a feature enabling an individual to work better or to create products well. Kauffeld (2006) found out that competencies were modifiable and could actively be fostered using new and complex tasks, within a didactic concept in education systems. Leekitchwatana (2017) stated that a competency consisted of knowledge and skill whereas supplementary or latent mental features might play supportive roles as necessary to shape this competency. Consequently, the term 'competency' simply defines as the high and effective performance which can be in form of knowledge, skills or attitude. In addition, it plays a dominant part in the area of human resource as it is used as an essential requirement for the recruitment process as well as appraisal process.

In educational settings, competency refers to a set of values, knowledge and skills which any professional teachers have to possess in order to be qualified in the profession of teaching (Grossman, 1990). All teachers are expected to gain those teaching competencies through training for successful completion of the teacher education programme (Houstan, 1987 cited in Bakhru, 2015). The teacher competences can be generally categorized to core knowledge and skills necessary for managing, teaching and learning (Cochran Smith et al., 2008). The other group, the functional competencies, are regarded as technical knowledge and abilities related to specific fields or tasks within the subject areas concerned (Brinckmann, 2008; Wayne \& Youngs, 2003). The teacher competencies have become a matter of vital importance as they are considered one of the critical factors for students' achievements either academic performance or personal development. (Kishwar Naz, 2016). Apart from that, much research has proven that the elevated academic performances of students were a result of qualified teachers with functional competencies (Babu \& Mendro, 2003; Sanders \& Rivers, 1996; Koster et al., 2005). Babu \& Mendro (2003) and his colleagues stated that the teachers with functional competencies are one of the key factors of student success since they separate effective teachers with functional capabilities from ineffective ones. In addition, Koster (2005) and his colleagues found out that the educators who possessed highly level of functional competencies were able to provide instructions, give guidance and support to student teachers effectively, thus, rendered substantial contribution to the development of students into competent teachers.

In Thailand, the Office of the Education Council Ministry of Education (2016) proposes that the functional competencies of Chinese teachers are highly required for managing a classroom of Chinese language learning effectively. However, it only states in general that functional competencies of teaching professional guidelines may consist of 9 areas of competences as follows; 1) Language and Technology for Teachers; 2) Curriculum Development; 3) Psychology for Teachers; 4) Educational Measurement and Evaluation; 5) Classroom Management; 6) Educational Research; 7) Educational Innovation; 8) 
Information Technology; and 9) Spirituality of teacher (Office of the Basic Educational Commission, Ministry of Education of Thailand, 2016). In addition, some studies have proposed the components of Chinese Language Teacher's Competencies. Yen Ye (2017) reported the components of Chinese Language Teacher's Competencies which included 1) Creation of a Conducive Classroom Environment; 2) Psychology of Learning; 3) Development of Teacher Professionalism; and 4) Understanding of Multiculturalism. Office of Chinese Language Council International (2007) specifying that the components of Chinese Language Teacher's Competencies could be as follows: 1) Chinese Curriculum and Curriculum Development; 2) Creation of a Conducive Classroom Environment; 3) Psychology of Learning and 4) ICT for Instructional Media Production. Phongphan (2015) found 5 components as follows: 1) ICT for Instructional Media Production; 2) Psychology of Learning; 3) Development of Teacher Professionalism; 4) Understanding of Multiculturalism and 5) Creation of a Conducive Classroom Environment. Chen Zhu (2015) suggested that the components of Chinese Language Teacher's Competencies could be as follows: 1) Development of Teacher Professionalism; 2) Creation of a Conducive Classroom Environment; 3) Chinese Curriculum and Curriculum Development and 4) Communication Skills and Knowledge. Certificate for Teachers of Chinese to Speakers of Other Languages (2019) specifically the Chinese Language Teacher's Competencies components are 1) Development of Teacher Professionalism; 2) Creation of a Conducive Classroom Environment; 3) Communication Skills and Knowledge and 4) Chinese Curriculum and Curriculum Development. Li Juan (2014) reported the components of Chinese Language Teacher's Competencies which included 1) Understanding of Multiculturalism; 2) Psychology of Learning and 3) ICT for Instructional Media Production. Chris Livaccari (2019) found out 5 components of Chinese Language Teacher's Competencies as follows: 1) Creation of a Conducive Classroom Environment; 2) Communication Skills and Knowledge; 3) Chinese Curriculum and Curriculum Development; 4) ICT for Instructional Media Production and 5) Development of Teacher Professionalism. Based on the literature review mentioned above, the synthesis of the core components found consisted of 7 components as follows : 1) Chinese Curriculum and Curriculum Development; 2) Creation of a Conducive Classroom Environment; 3) Psychology of Learning; 4) Development of Teacher Professionalism; 5) Communication Skills and Knowledge; 6) Understanding of Multiculturalism and 7) ICT for Instructional Media Production. Though these components were scientifically studied, they were not statistically analyzed in order to find out that the theoretical data were concurrent with the empirical data. Thus, the focus of this study was aimed at applying Confirmatory Factor Analysis (CFA) as the technique that uses mathematical procedures for the simplification of interrelated measures to discover patterns in a set of variables (Harman, 1976). Simply stated, it is used for testing whether measures of a construct are consistent with a researcher's understanding of the nature of that construct or factor. CFA has emerged as the single most widely used and recommended means for analyzing (Becker \& Cote, 1994). It has been used more and more these days especially in areas of behavioral and social sciences (Yong \& Pearce, 2013). 
Therefore, this research was conducted to affirm these 7 components of Chinese language teacher's functional competencies in Thai schools of Basic Education with a confirmatory factor analysis method. The results of this study can be used as guidelines for Chinese teachers in planning their individual development plan. Furthermore, these results may be utilized for educational administrators in the areas of human resource development for assuring the decent quality of Chinese language teachers.

\section{METHOD}

This research applied a quantitative methodology which examined the construct validity of Chinese language teacher functional competencies with the empirical data. The tool of the study was the questionnaires with its reliability of 0.96 and the data collected was investigated statistically with Confirmatory Factor Analysis. The procedures for this examination included the samples selection, the data collection and the data analysis as follows.

\section{Sample Selection}

To select the samples, stratified random sampling technique was applied. The sample size was determined following the methods by Hair, Black, Babin, \& Anderson (2010) which stated that in analysing the components, researchers commonly use a sample size from 5 to 20 times larger than the number of observed variables. In this study, there were 20 observed variables, thus, allowing a total sample size ranging from $105-420$. Therefore, 500 Chinese language teachers were selected from the population of Chinese language teachers in schools of a basic education commission from 4 regions of Thailand and 42 Central Educational Service Area Office with the total number of 901 Chinese language teachers (Office of the Education Council Ministry of Education, 2018). Those samples were taken from 4 regions of Thailand including 1) Central Educational Service Area Office of 12 areas (302 population, 168 samples) 2) Northern Educational Service Area Office of 9 areas (173 population , 96 samples) 3) Northeastern Educational Service Area Office of 15 areas (299 population ,166 samples) 4) Southern Educational Service Area Office of 6 areas (127 population ,70 samples), totaling 500 samples.

\section{Data Collection}

To collect the data, the questionnaire which was designed and verified for its reliability of 0.96 was utilized for this study. It consisted of 54 questions contributing in 7 components as follows: 1) Chinese Curriculum and Curriculum Development ( Reliability $=.892)$; 2) Creation of a Conducive Classroom Environment (Reliability $=.929)$; 3) Psychology of Learning (Reliability $=.945)$; 4) Development of Teacher Professionalism (Reliability $=.937)$; 5) Communication Skills and Knowledge $($ Reliability $=.913) ; 6)$ Understanding of Multiculturalism (Reliability $=.914)$, and 7) ICT for Instructional Media Production (Reliability $=.845$ ) These components as the variables were synthesized based on the studies of Yan Ye (2017); Office of Chinese Language Council International (2007); Phongphan (2015); Chen Zhu (2015); Certificate for Teachers of Chinese to Speakers of Other Languages (2019); Li Juan (2014); Chris Livaccari (2019). Then, the data were collected by distributing the 
questionnaire to the participants who were Chinese language teachers in Thai schools of the Basic Education Commission. The 494 questionnaires were returned (98.80\%) and they were checked for their completion before the analysis process.

\section{Data Analysis}

The data were analysed in 2 stages as follows.

1. The confirmatory analysis was used to examine the construct validity of Chinese language teacher functional competencies with the empirical data. Confirmatory Factor Analysis (CFA) performs its function as a multivariate analysis for testing concepts based on multiple measured indicators (Hair et al., 2010). Estimation methods in CFA include a maximum likelihood factor that determines the optimal value of the factor loading. A valid indicator can be used as convergence if the loading value on standard regression weight is higher than 0.5 or $\mathrm{p}<\alpha=.05$, the chi squared $\left(\chi^{2}\right)$ value is small, the significance probability is higher than .05 ( $\mathrm{p}>.05), \chi^{2} / \mathrm{df}$ is lower than 2.00 (Bollen,1989), RMR is lower than 0.08 (Hu \& Bentler,1999), GFI is higher than 0.09 (Byrne, 2001), AGFI greater than or equal 0.90 (Schumacker \& Lomax ,2010) and RMSEA is lower than 0.08 (Schumacker \& Lomax , 2010). This method consisted of the Kaiser-Meyer-Olkin (KMO) test was utilized to find the suitability of the data $(0.755$ $=$ good $)($ Joreskog \& Sorbom, 1999). Bartlett's Test of Sphericity to measure the sampling adequacy $(1947.717$, p-Value $=0.00)$. Pearson's Correlation Coefficients was tested to find out the relationship between each pair of observed variables. Therefore, it could be confirmed that the test results were in accordance with the preliminary agreement. CFA was examined to check the validity of the model by LISREL 8.54. This analysed the fit of a model and its respective parameter estimates.

2. The data were analysed with descriptive statistics; Mean (M) and Standard Deviation (S.D.) first to find out the sequence and importance of each component.

\section{FINDINGS}

The research findings were shown in 2 parts as follows;

Part 1 reported the results for Confirmatory Factor Analysis (CFA) of Chinese language teacher's functional competencies components as shown in Table 1-2 and Figure 1. 
Table 1

Significant Results of the Variables and Their Interrelationship

\begin{tabular}{|c|c|c|c|c|c|c|c|}
\hline Variables & CD & $\mathrm{CE}$ & PL & DT & CK & UM & IT \\
\hline $\begin{array}{l}\text { Chinese Curriculum and } \\
\text { Curriculum Development (CD) }\end{array}$ & 1.000 & & & & & & \\
\hline $\begin{array}{l}\text { Creation of a Conducive } \\
\text { Classroom Environment (CE) }\end{array}$ & $.614 * *$ & 1.000 & & & & & \\
\hline Psychology of Learning (PL) & $.521 * *$ & $.803 * *$ & 1.000 & & & & \\
\hline $\begin{array}{l}\text { Development of Teacher } \\
\text { Professionalism (DT) }\end{array}$ & $.530 * *$ & $.797 * *$ & $.830 * *$ & 1.000 & & & \\
\hline $\begin{array}{l}\text { Communication } \\
\text { Skill and Knowledge (CK) }\end{array}$ & $.457 * *$ & $.552 * *$ & $.606 * *$ & $.663 * *$ & 1.000 & & \\
\hline $\begin{array}{l}\text { Understanding of } \\
\text { Multiculturalism (UM) }\end{array}$ & $.404 * *$ & $.600 * *$ & $.717 * *$ & $.626^{* *}$ & $.673 * *$ & 1.000 & \\
\hline $\begin{array}{l}\text { ICT for Instructional Media } \\
\text { Production (IT) }\end{array}$ & $.490 * *$ & $.701 * *$ & $.716 * *$ & $.662 * *$ & $.584 * *$ & $.693 * *$ & 1.000 \\
\hline
\end{tabular}

From the table 1, the relationship test of the variables showed that the studied variables were correlated with statistical significance at the level of 0.01 . The highest correlated variables were Development of Teacher Professionalism (DT) and Psychology of Learning (PL) with the relationship value of 0.830 , followed by Psychology of Learning (PL) and Creation of a Conducive Classroom Environment (CE) with the relationship value of 0.803 . The least correlated which Understanding of Multiculturalism (UM) and Chinese Curriculum and Curriculum Development (CD) value of 0.404 . When all correlated variables exceed 0.30 as determined by the specified criteria, then these variables are appropriate for Confirmatory Factor Analysis.

Table 2

Confirmatory Factor Analysis Results for Chinese Language Teacher's Functional Competencies Components

\begin{tabular}{lllll}
\hline Goodness-of-fit index & Criteria & Statistics & Outcome & Reference \\
\hline$\chi^{2}$-test & P-value exceeds 0.05 & 0.81 & Passed & Byrne (2001) \\
$\chi 2 /$ df & $<2.00$ & 0.12 & Passed & Bollen (1989) \\
RMR & $<0.08$ & 0.00 & Passed & Hu \& Bentler (1999) \\
GFI & $>0.90$ & 1.00 & Passed & Byrne (2001) \\
AGFI & $\geq 0.90$ & 0.99 & Passed & Schumacker\&Lomax (2010) \\
RMSEA & $<0.08$ & 0.00 & Passed & Schumacker\&Lomax (2010) \\
\hline
\end{tabular}

From table 2 the statistical analysis revealed that, at the 0.05 significant level, the pvalue was 0.81 . The goodness of fit index (GFI) was 1.00 , while the adjusted goodness of fit index (AGFI) was calculated as 0.99. Both GFI and AGFI confirmed that this was a good fitting model as they both exceeded 0.90. RMR was lower than 0.08. Then the root means the square error of approximation (RMSEA) was 0.00. It can be confirmed that there was consistency across the defined criteria with a value of less than 0.08 . Overall, the results of the confirmed component analysis were consistent with the empirical data. When considering the weight value of the components, it was found that 
the analysis results were confirmed and the weights of all the variables were statistically significant at the 0.05 level.

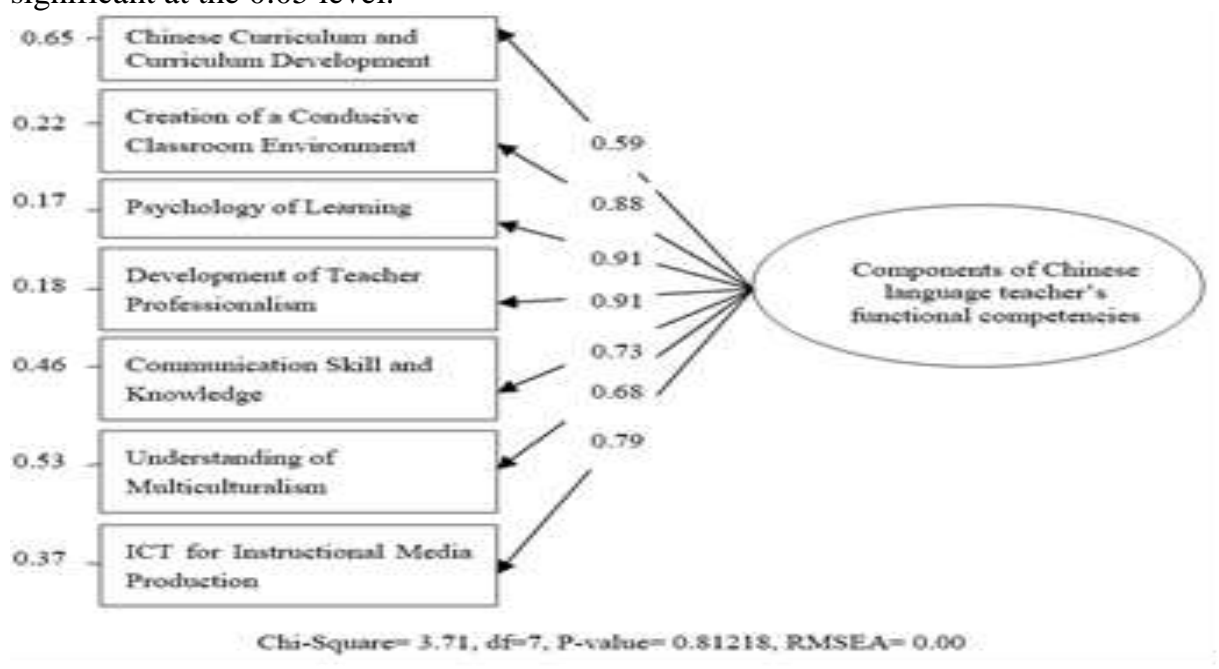

Figure 1

Confirmatory Factor Analysis Results for Chinese Language Teacher's Functional Competencies Components

From Figure 1, When considering the weights, it was found that Chinese Curriculum and Curriculum Development $=0.59$, Creation of a Conducive Classroom Environment $=$ 0.88 , Psychology of Learning $=0.91$, Development of Teacher Professionalism $=0.91$, Communication Skill and Knowledge $=0.73$, Understanding of Multiculturalism $=0.68$ and ICT for Instructional Media Production $=0.79$.

Part 2 revealed the opinions of the Chinese language teacher's functional competencies in Thailand as shown in Table 3.

Table 3

The Opinions of Chinese Language Teacher's Functional Competencies

\begin{tabular}{llll}
\hline Components & Mean & Std. Deviation & Meaning of results \\
\hline Chinese Curriculum and Curriculum Development & 4.26 & 0.50 & Highest \\
\hline Creation of a Conducive Classroom Environment & 4.28 & 0.42 & Highest \\
\hline Psychology of Learning & 4.32 & 0.49 & Highest \\
\hline Development of Teacher Professionalism & 4.27 & 0.59 & Highest \\
\hline Communication Skill and Knowledge & 4.66 & 0.39 & Highest \\
\hline Understanding of Multiculturalism & 4.48 & 0.43 & Highest \\
\hline ICT for Instructional Media Production & 4.35 & 0.47 & Highest \\
\hline
\end{tabular}

From the table 3 , it was found that all components were placed highest ranging from 4.26 - 4.66. The highest one was Communication Skill and Knowledge (4.66) while the lowest one was the component of Chinese Curriculum and Curriculum Development (4.26). 


\section{DISCUSSION}

The findings from CFA method revealed that these seven functional competencies of Chinese language teachers in Thailand were testified as essential for qualified Chinese language teachers through the validation of goodness of a fitted model. When considering the weight value of each component, Psychology of Learning and Development of Teacher Professionalism have the highest weights determined through the measurement model. This could reflect that both components play a leading role as compulsory components of Chinese language teacher's functional competencies. Such findings concur with the findings from the study by Chen Zhu \& Alexander Yeung (2015) on self-efficacy in teaching Chinese as a foreign language in Australian schools that learning psychology is an important component for teachers because it enables teachers to understand that Chinese language students have different perceptions. At the same time, Chen (2011) and Huang (2011) also concluded from their studies that Chinese language teachers should understand learning psychology because basic knowledge of psychology enables teachers to categorize students and design learning activities to be interesting and responding to the needs of students who learn Chinese as their second language. In addition, Hill, Ball, \& Schilling (2008) also pointed out that some teachers may have good knowledge of the subject but lack of learning psychology, which makes Chinese language learning unsuccessful because it is difficult to adjust teaching and learning activities for Chinese language to fit students whose first languages are non- Chinese. Teachers lacking of psychological knowledge may fail in helping students learn Chinese language. As Phongphan (2015) explained, the teachers were required to use psychology to motivate their learners. In addition, Aksoy (2016) found that knowledge of psychological factors involved in the process of language learning and teaching were indispensable for teachers who teach languages. In terms of Development of Teacher Professionalism, the research and education development of Office of the Education Council Ministry of Education Thailand (2016) related it to the ability of teachers' knowledge, attitudes and skills in educating and teaching including the ability to understand students. The research suggests that to increase the Development of Teacher Professionalism, teachers should engage in activities that include education, teaching and learning process and professional development. The findings from that study also correspond with the findings from the study by Mohammad Attaran \& Hu Yishuai (2018) on teacher education curriculum for teaching Chinese as a foreign language that the development of the professional teachers and the building of professional identities of teachers were greatly important to the development of learning and teaching because it was believed that professional teachers will have their own techniques to teach and to develop themselves, which is an essential component that leads to the change in education. Such findings concur with the study by Duff \& Lester (2008) that the efficiency of teachers is caused by profession building and development of competencies, skills and attributes. In addition, Wang et al., (2014) studied on learning and development of teacher professionalism which could be regarded as precious teacher's functional competencies for Chinese teaching and learning process. These two components should be paid higher attention when it comes to designing guidelines or plans that enable all Chinese language teachers to improve their 
professional capacities and achieve the quality of Chinese teaching and learning after all.

Apart from that, the results showed that all the 7 components were considered essential. In the opinions of the respondents, the top important components are Communication Skill and Knowledge, with means of 4.66 and S.D. of 0.39 , Understanding of Multiculturalism with means of 4.48 (M) and S.D. of 0.43 and ICT for Instructional Media Production with means of 4.35 and S.D. of 0.47 .

Based on the results, unsurprisingly, the component of Communication Skill and Knowledge was drawn highest attention as it was placed the first rank among the 7 components because it is common to believe that the qualified teachers must possess the knowledge which should be beyond students' knowledge and they must deliver such the knowledge through effective communication skills. Thus, all teachers are to be trained continuously with various pedagogical approaches which communication skills are embedded. Moreover, the findings from the study by Xia Wu (2011) pointed out that knowledge and communication skills are important components that should be developed in teachers so that they will have insights in the contents of the subjects teach and can use Chinese language accurately in communicating leading to well-orgazined and smooth teaching and learning activities. This idea concurs with the findings from the study by Chatbamrungsuk (2016) who discovered that Chinese language teachers must have the fundamental knowledge of language and communication, which are regarded as necessary competencies. Educational agencies must provide training and development in several forms so that teachers will have linguistic knowledge and skill of communication in Chinese language, which can be applied in order to improve students' knowledge and competencies. Likewise, Lu \& Zhao (2008) concluded the findings from his study that Chinese language teachers must focus on students' knowledge and usage of language by aiming to the development of the listening, speaking, reading and writing skills through classroom activities held by teachers. This is similar to the findings from the study by Chris Livaccari (2019) who explained that Chinese language teachers need to add a new set of standards that go beyond language proficiency, especially Chinese communication skill and culture knowledge. If the teachers want to develop their ability to interact with others in the community of the target language and culture, they need to expand not only linguistic knowledge but also pragmatic understanding. Hence, the component of Communication Skill and Knowledge is unsurprisingly most needed for the qualified Chinese language teachers.

The next component, Understanding of Multiculturalism, refers to the competencies of knowledge extension, construction and expansion based on attitudes and cultural skills such as traditions, customs, language, religion, beliefs, costumes, and way of life. This concurs with the findings from the study by Huanshu Yuan (2017) on multicultural teacher education in China: preparing culturally responsive teachers in a multiethnic and multicultural country, which pointed out that the diversity and the complexity of culture are basic components that should be developed in Chinese language teachers in order to build understanding and foundation for teaching arrangement. Furthermore, Geneva \& Tyrone (2000) discovered that the development of teachers' competencies that are 
related to the study on different cultures can partly help the integration of the teaching arrangement method and identification of proper teaching techniques. This is agreeable to the idea of Krasnof (2016) who stated in their study that teachers with multi-cultural understanding can arrange teaching and learning that enhance students' intellectual and social skills on the bases of cultures in order to build students' good knowledge, skills and attitudes in the environment of cultural diversity. Also, the concept of the competencies of Chinese language teachers in the component of understanding of multiculturalism is also concurrent with the concept by Jin Jie Ming (2010) who proposed that Chinese language teachers must integrate language teaching and cultural teaching in the way most similar to the native speakers. Teachers need the development in this aspect such as to learn about cultures in Chinese contexts, to use language teaching techniques whereby cultural is also taught about, and, most importantly, to have insights of multiculturalism.

The third component, ICT for Instructional Media Production are vital tools for designing teaching activities that help students achieve learning objectives more easily. This concept concurs with the findings from the report by Liu, Goh, \& Zhang (2006) on the role of technology in teaching and learning Chinese characters, which confirmed that effective technologies, material and innovations help teaching and learning, especially the teaching of Chinese characters through technologies which enables learners to understand Chinese characters faster and to memorize more characters. Therefore, Chinese language teachers should be equipped with ICT for Instructional Media Production since it is becoming necessary to create up-to-dated lessons such as animations to develop reading and writing skills (Cai \& Zhu, 2012). This is in accordance with the findings from the study by Sunthonchamon (2016) who discovered that teachers with technology-related skills to produce innovations for teaching and learning activities will be motivators to urge students to realize that Chinese language is significant and it is believed that this helps increase the students' desire to learn. The idea of this functional component of Chinese language teachers is concurrent with the findings from the study by Cheng, Zhan\& Tsai (2010) on integrating second life into a Chinese language teacher training program: A pilot study, which confirmed that the competency of innovative material creation is a fundamental competency of Mandarin Chinese language teachers because innovative materials enable students to understand the contents and review lessons more easily. When Chinese language teachers possess competencies that are related to technologies, material production, innovation and computer literacy, they can create new learning materials to build extended bodies of knowledge to students and enhance continuous learning skills.

\section{CONCLUSION}

With the CFA technique, the findings were proven that the seven components of Chinese language teacher's functional competencies correspond significantly with empirical data. They include 1) Curriculum and Curriculum Development, 2) Creation of a Conducive Classroom Environment, 3) Psychology of Learning, 4) Development of Teacher Professionalism, 5) Communication Skill and Knowledge, 6) Understanding of Multiculturalism, and 7) ICT for Instructional Media Production. Regarding descriptive 
statistical analysis of means and standard deviation, these seven components were found compulsory for being the components of qualified Chinese language teachers of Thai schools of basic education. Furthermore, these components may be further developed as indicators as well as components in a model for developing Chinese language teacher's functional competencies in order to improve teacher quality and students' learning achievement in Chinese language in Thailand. Moreover, the findings may serve any educational institutions with this set of components as the information necessary for planning and developing the policy for recruiting quality Chinese language teacher in the long run.

\section{SUGGESTIONS}

From this study, the practicality of these components could be used as a competency framework for recruiting new Chinese language teachers and assessing their performance. Also, it is strongly recommended that these components could be examined with the second order confirmatory analysis to develop the indicators for measuring the Chinese language teaching competency in Thailand.

\section{REFERENCES}

Aksoy, K. (2016). Review of exploring psychology in language learning and teaching. Eurasian Journal of Applied Linguistics, 2(1), 65-70.

Attaran, M., \& Yishuai, H. (2018). Teacher education curriculum for teaching Chinese as a foreign language. MOJES: Malaysian Online Journal of Educational Sciences, 3(1), 34-43.

Babu, S., \& Mendro, R. (2003). Teacher accountability: HLM-based teacher effectiveness indices in the investigation of teacher effects on student achievement. Paper presented at the AERA Annual Conference. Chicago: IL.

Bakhru, K. M. (2017). Personal competencies for effective teaching: A review based study. Educational Quest, 8, 297-303.

Basha, K. (2016). Culturally responsive teaching: A guide to evidence-based practices for teaching all students equitably. Portland: Region X Equity Assistance Center at Education Northwest.

Becker, T. E., \& Cote, J. A. (1994). Additive and multiplicative method effects in applied psychological research: An empirical assessment of three models. Journal of Management, 20(3), 625-641.

Bennett, C., Niggle, T., \& Stage, F. (1990). Pre-service multicultural teacher education: Predictors of student readiness. Teaching and Teacher Education, 6(3), 243-254.

Bollen, K. A. (1989). A new incremental fit index for general structural equation models. Sociological Methods \& Research, 17(3), 303-316.

Boyatzis, R. (1982). The competent manager: A model for effective performance. Chichester: John Wiley. 
Brinckmann, J. (2008). Competence of top management teams and success of new technology-based firms. Wiesbaden: Gabler.

Byrne, B. M. (2001). Structural equation modeling with AMOS, EQS, and LISREL: Comparative approaches to testing for the factorial validity of a measuring instrument. International Journal of Testing, 1(1), 55-86.

Cai, S., \& Zhu, W. (2012). The impact of an online learning community project on university Chinese as a foreign language students' motivation. Foreign Language Annals, 45(3), 307-329.

Chinese Teacher Training Center. (2019). Certificate for teachers of chinese to speakers of other languages. Retrieved from https://www.tcsol.us/

Chen, H. (2011). A Chinese beginning teacher's professional identity transformation: An auto-ethnographic study (Unpublished master thesis). University of Western Sydney, Australia.

Chen, Z., \& Yeung, A. S. (2015). Self-efficacy in teaching Chinese as a foreign language in Australian schools. Australian Journal of Teacher Education, 40(8), 2.

Cheng, H. J., Zhan, H., \& Tsai, A. (2010). Integrating second life into a Chinese language teacher training program: A pilot study. Journal of Technology and Chinese Language Teaching, 1(1), 31.

Chris Livaccari. (2019). Global competence for Chinese language teachers. Retrieved from https://asiasociety.org/china-learning-initiatives/global competence-Chineselanguage-teachers.

Duff, P., \& Lester, P. (2008). Issues in Chinese language education and teacher development. Vancouver: Centre for Research in Chinese Language and Literacy Education.

Cochran-Smith, M., Feiman-Nemser, S., McIntyre, D. J., \& Demers, K. E. (2008). Handbook of research on teacher education: Enduring questions in changing contexts. New York: Routledge.

Geneva G., \& Tyrone C. H. (2000). Multicultural teacher education for the $21^{\text {st }}$ century. The Teacher Educator, 36, 1-16.

Grossman, P. (1990). The making of a teacher: Teacher knowledge and teacher education. New York: Teachers College Press.

Hair, J. F., Black, W. C., Babin, B. J., \& Anderson, R. E. (2010). Multivariate data analysis: A global perspective. New Jersey: Pearson.

Harman, H.H. (1976). Modern factor analysis. Chicago, IL: University of Chicago.

Hill H. C., Ball, D. L., \& Schilling, S. G. (2008), Unpacking pedagogical content knowledge: Conceptualising and measuring teachers' topic-specific knowledge of students. Journal for Research in Mathematics Education, 39(4), 372-400. 
Hu, L.-t., \& Bentler, P. M. (1999). Cutoff criteria for fit indexes in covariance structure analysis: Conventional criteria versus new alternatives. Structural Equation Modeling, $6(1), 1-55$.

Huang, X. (2011). A 'self-study' of a Chinese teacher-researcher's practice of transnational knowledge exchange: Stimulating students' Mandarin learning in Australia (Unpublished master thesis). University of Western Sydney, Australia.

Jin Jie Ming. (2010). Duiwai Hanyu jiaoxue changyong kechang jiaoxuefa. Zhongwen daxi yuandi.

Joreskog, K. G., Sorbom, D., Du Toit, S., \& Du Toit, M. (1999). LISREL 8: New statistical features. Chicago: Scientific Software International, 6-7.

Kauffeld, S., 2006. Self-directed work groups and team competence. Journal of Occupational and Organizational Psychology, 79(1),m1-21.

Kishwar ,N. (2016). Effects of teachers' professional competence on students' academic achievements at secondary school level in Muzaffarabad District, Munich, GRIN Verlag, Retrieved from: https://www.grin.com/document/352095

Koster, B., Brekelmans, M., Korthagen, F., \& Wubbels, T. (2005). Quality requirements for teacher educators. Teaching and Teacher Education, 21(2), 157-176.

Leekitchwatana, P. (2017). Development of competency factors for information technology. KKU Research Journal, 15(11), 1101-1113.

Li Juan. (2014). Needs for skill development among Chinese teacher in school Chonburi province (Unpublished master thesis) Burapha University, Chonburi, Thailand.

Liu, Y., Goh, H. H., \& Zhang, D. (2006). A preliminary description of Singaporean Chinese language classrooms. Chinese Teaching of the World, 1, 97-105.

Lloyd, C., \& Cook, A. (1993). Implementing standards of competence: Practical strategies for industry. London: Kogan Page.

Lu, J. \& Zhao, Y. (2011). Teaching Chinese as a foreign language in China: A profile, in Teaching and learning Chinese in global contexts. London: Continuum International.

McClelland, D. C. (1973). Testing for competence rather than for "intelligence". American psychologist, 28(1), 1.

Office of Chinese Language Council International. (2019). Chinese tests. Retrieved from http: //www. english.hanban.org/node_9906.html.

Office of the Basic Educational Commission, Ministry of Education of Thailand. (2016). The professional standards of teaching profession. Bangkok: Kurusapa Ladprao. 
Office of the Education Council Ministry of Education. (2016). Research report for the development of Chinese language teaching in Thailand Secondary level. Bangkok: Prigwan Graphic.

Office of the Education Council Ministry of Education. (2018). Education in Thailand. Bangkok: Prigwan Graphic.

Chatbamrungsuk, P. (2016). Research report for the development of Chinese language teaching in Thailand Secondary level. Bangkok: Prigwan Graphic.

Sanders, W. L., \& Rivers, J. C. (1996). Cumulative and residual effects of teachers on future student academic achievement (Unpublished research progress report). University of Tennessee Value-Added Research and Assessment Center.

Schumalker R. E., \& Lomax. (2010). A beginners guide to structural equation modeling. New York: Routledge Taylor \& Frances Group.

Spencer, L. M., \& Spencer, S. M. (1993). Competency at work: Models for superior performance. New York: John Wiley \& Sons.

Wang, L., Lai, M., \& Lo, L. N. K. (2014). Teacher professionalism under the recent reform of performance pay in Mainland China. Prospects, 44(3), 429-443.

Phongphan, W. (2015). The competencies promotion of Chinese language teacher in secondary school in the eastern region of Thailand. Journal of Education and Social Development, 11(1), 98-111.

Sunthonchamon, W. (2016). Research report for the development of Chinese language teaching in Thailand Synthesis overview. Office of the Education Council Ministry of Education Bangkok, Prigwan Graphic.

$\mathrm{Wu}, \mathrm{X}$. (2011). Teaching communication in the Chinese as a foreign language classroom. All graduate plan b and other reports. Utah State University

Ye, Y. (2017). A study on Chinese teachers' competence, challenges and ability to handle the challenges at international Schools in Bangkok, Thailand. PSAKU International Journal of Interdisciplinary Research, 6(1), 1-8.

Yong, A. G., \& Pearce, S. (2013). A beginner's guide to factor analysis: Focusing on exploratory factor analysis. Tutorials in Quantitative Methods for Psychology, 9(2), 7994.

Yuan, H. (2017). Multicultural teacher education in China: Preparing culturally responsive teachers in a multiethnic and multicultural country. US-China Education Review, 7(2), 85-97.

Yue, Y. (2017). Teaching Chinese in K-12 schools in the United States: What are the Challenges? Foreign Language Annals, 50(3), 601-620.

Zhan, H., \& Cheng, H. J. (2014). The role of technology in teaching and learning Chinese characters. International Journal of Technology in Teaching and Learning, 10(2), 147. 